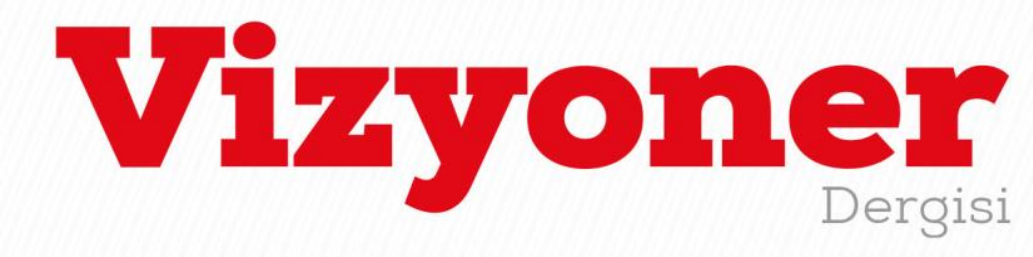

Süleyman Demirel Üniversitesi Vizyoner Dergisi, Yıl: 2020, Cilt: 11, Sayı: Ek, 29-41.

Süleyman Demirel University Visionary Journal, Year: 2020, Volume: 11, No: Supplement, 29-41.

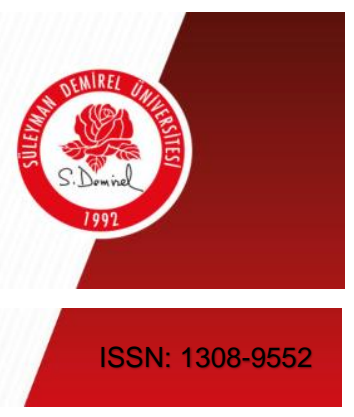

\title{
SAĞLIK ÇALIŞANLARININ SANAL KAYTARMA ETKİNLİKLERİ VE SÜRELERIं*
}

\section{CYBERLOAFING ACTIVITIES AND THEIR DURATIONS AMONG HEALTHCARE PROFESSIONALS}

\author{
Doç. Dr. Sedat BOSTAN ${ }^{1}$ \\ Öğr. Gör. Mustafa FíLiZz
}

\section{ÖZ}

$\mathrm{Bu}$ çalışmanın amacı, sağlık çalışanlarının mesai süreleri içerisinde iletişim teknolojilerini kullanarak yapmış oldukları sanal kaytarma nedenlerini ve sürelerini tespit etmek ve sanal kaytarmanın sağlık kurumlarına maliyeti konusunda bir farkındalık oluşturmaktır. Bu süreçte sanal kaytarma sürelerini ölçmeye yönelik bir ölçeğe sahip olmaktır. Araştırmanın evrenini Artvin Devlet Hastanesinde ve Arhavi Devlet Hastanesinde çalışmakta olan toplam 326 sağlık çalışanı, örneklemini ise ankete gönüllü katılmayı kabul eden 133 sağlık çalışanı oluşturmaktadır. Anketin ölçeği daha önceki çalışmalardan yararlanılarak geliştirilmiştir. Ölçek demografik değișkenler dişında on beş ifadeden oluşmaktadır. Ölçek faktör analiziyle geçerlenerek, Cronbach's Alpha katsayısıyla güvenirliği test edilmiş ve uygun bulunmuştur. Her maddeyle ve ortalamayla ilgili sanal kaytarma sürelerinin hesaplanmasında gruplanmış seriler için aritmetik ortalama hesaplanması tekniği kullanılmıştır. Elde edilen bulgulara göre örneklemdeki sağlık çalışanları normal hayatlarında ortalama kişi başı günlük 203 dakikasını, haftalık 1427 dakikasını sanal âlemde geçirmektedir. Bu sürenin ortalama 452 dakikasını (7,5 saat) haftalık mesai süresi içerisinde yapmaktadır. En fazla zaman alan sanal kaytarma faaliyetleri; kişisel sosyal medya araçlarını kullanma (54 dakika) ve dizi, film, maç vb. programları izleme (52 dakika) etkinliğidir. Çalışmada erkekleri kadınlara göre, lise mezunlarının diğer gruplara göre daha fazla sanal kaytarma yaptıkları görülmüştür.

Anahtar Kelimeler: Sağlık Çalışanı, Sağlık Sektörü, Sanal Kaytarma, Sanal Kaytarma Süreleri, Sanal Kaytarma Ölçeği.

JEL Sınıflandırma Kodları: I18, M15, O33.

\begin{abstract}
The purpose of the study is to identify the causes and durations of cyberloafing that healthcare professionals make using their communication technologies during working hours and to raise awareness about the cost of cyberloafing to healthcare institutions. In this process, it is necessary to have a scale to measure cyberloafing durations. The population of the study is 326 healthcare workers working in Artvin State Hospital and Arhavi State Hospital, and 133 healthcare workers who agree to participate in the survey voluntarily. The scale of the questionnaire is developed based on previous studies. The scale consists of fifteen expressions other than demographic variables. The scale is validated with factor analysis and its reliability is tested and found to be appropriate with Cronbach's Alpha coefficient. Arithmetic mean for batches that are grouped in calculating

Artvin Çoruh Üniversitesi Bilimsel Araştırma ve Yayın Etiği Kurulu tarafından incelenmiş, kurulun 05.12.2018 tarihli ve E.20010 sayılı kararıyla etik yönden uygun olduğu belirlenmiştir.

1 (D) Ordu Üniversitesi, Sağlık Bilimleri Fakültesi, Sağlık Yönetimi Bölümü, sbostan29@gmail.com

2 (D) Artvin Çoruh Üniversitesi, Sağlık Hizmetleri Meslek Yüksekokulu, Tıbbi Hizmetler ve Teknikler Bölümü, mustafa2108@artvin.edu.tr

Makale Geliş Tarihi / Received : : 16.04.2020

Makale Kabul Tarihi / Accepted $\quad$ : 17.08.2020

DOI: 10.21076/vizyoner.720897
\end{abstract}


Süleyman Demirel Üniversitesi Vizyoner Dergisi, Yıl: 2020, Cilt: 11, Sayı: Ek, 29-41.

Süleyman Demirel University Visionary Journal, Year: 2020, Volume: 11, No: Supplement, 29-41.

cyberloafing times for each item and average. According to the findings obtained, the health workers in the sample spend an average of 203 minutes per day and 1427 minutes per week in their virtual lives in their normal lives. It performs an average of 452 minutes (7.5 hours) of this period within the weekly working hours. Cyberloafing activities that take the most time; using personal social media tools (54 minutes) and TV series, movies, matches etc. is the activity of watching programs (52 minutes). In the study, it is observed that high school graduates and men make more cyberloafing compared to other groups of education and women, respectively.

Keywords: Health Worker, Health Sector, Cyberloafing, Cyberloafing Duration, Cyberloafing Scale.

JEL Classification Codes: I18, M15, O33.

\section{GíRiş}

Günümüzde internet ve internet kullanımı birey ve örgüt için vazgeçilmez bir ihtiyaç haline gelmiştir. Birey açısından en bariz örneği e-mail adresinin iletişim bilgilerinin içinde yer almasıdır. Örgütlerde hemen hemen tüm örgüt fonksiyonlarının internetle bütünleşmesi vazgeçilmez bir etken olduğunun göstergesidir (e-toplantılar, esınavlar, e pazarlama, online mülakatlar vb.). İnternetin toplumda kullanımın artması ile beraber yüz yüze ilişkiler azalmakta ve birçok işlem online yapılmaktadır (Ünal, Tekdemir ve Yaldızbaş, 2015: 517).

İnsanlık tarihine bakıldığı zaman birey başkasının işini yapmaya başlamasıyla beraber işle ilgili aksamalar veya diğer ifade ile kaytarmalar olduğu görülmektedir. İnsanlar işle ilgili sıkıntılardan kurtulmak veya işi yapmamak için çeşitli yollara teşebbüs etmiştir. Eski dönemlerde çalışanın iş yerinde işten kaytarabilmesi için çok az araç bulunurken günümüzde bu araçlar birden bine çıkmıştır. Özellikle internetle beraber sanal kaytarma gibi büyük bir kaytarma aracı ortaya çıkmıştır (Özkalp, Aydın ve Tekeli, 2012: 23). Örgütlerde internet erişiminin artması ile beraber işten kaytarma çağ atlamıştır (Lim, Tim ve Loo, 2002: 67). Mesai saatleri içerisinde iş ile ilgili gereklilikleri yerine getirmek amacıyla çalışana sunulan internet hizmetlerinin bireysel amaçlar için kullanılması olarak kabul edilen sanal kaytarma, sapkın bir davranış olarak kabul edilmektedir. Teknolojide ilerlemeler oldukça, kullanılabilirliği, erişilebilirliği, hızı ve entegrasyonu artıkça iş yerinde bireyler internetin yanlış kullanımı için yeni yollar deneyeceklerdir. Bunun bir sonucu olarak sanal kaytarma devamlı olarak güncelliğini koruyan bir konu olarak kalacaktır (Liberman, McKenna ve Buffardi, 2011: 2194).

Sanal kaytarma ile ilgili literatürde birçok tanım yapılmıştır. Sanal kaytarma; çalışanların mesai saati içerisinde internet, bilgisayar ve cep telefonu teknolojilerini bireysel amaçları için kullanmalarıdır (Lim, 2002; Vitak, Crouse ve LaRose, 2011). Özkalp vd., (2012) göre, “bilgi ve iletişim teknolojilerinin hem günlük hayatta hem de iş sürecinde yoğun bir şekilde kullanımı sonucu olarak çalışanların işten kaytarmak amacıyla zamanını boşa geçirmek ya da kendi amaçları doğrultusunda internet, Facebook ve kişisel elektronik mail kullanımlarından dolayı boşa geçen zamanlar" olarak tanımlanmıştır (Önsal, 2012: 241). Türkçe yazında sanal kaytarma "siber aylaklık" olarak da ifade edilmektedir (Kalaycı, 2010). Örücü ve Yıldız (2014)'ın yaptığı tanımda ise sanal kaytarma, çalışanın iş görmesi amacıyla kendisine tahsis edilen bilgisayar ve internet sistemlerini özel amaçları için kullanılmasıdır. Diğer bir tanıma göre ise sanal kaytarma, mesai saatlerinde, çalışanların kendi istekleri ile bilişim araçlarını mevcut işleriyle alakası olmayan amaçlar doğrultusunda kullanmasıdır (Ünal ve Tekdemir, 2015: 98).

Literatürde sanal kaytarma ilgili çeşitli sınıflandırmalar mevcuttur. En yaygını ise önemli sanal kaytarma ve önemsiz sanal kaytarma şeklindedir (Lim vd., 2002; Blanchard ve Henle, 2008: 1068). Önemli sanal kaytarma: bu tip sanal kaytarmalarda hem işveren açısından hukuki boyutu bulunmakta hem de çalışan açısından verimsizliğe ve ciddi vakit israfına neden olmaktadır. Örneğin online kumar oynamak, cinsel içerikli siteler, açık artırımlara katılmak vb. aktiviteleri içermektedir. Önemsiz sanal kaytarma ise anlık aktiviteleri kapsamaktadır. Çalışanların iş ile ilgili verimliliklerine ciddi boyutta etkisi bulunmamaktadır. Bu tip sanal kaytarma davranışının öğrenmeye katkısının olduğunu savunan bilim adamları da olmuştur. Diğer yandan fazla vakit almayan ve çok sık tekrarlanmayan önemsiz sanal kaytarma davranışlarının işe olumlu katkı sağladığı ve hukuki boyutta herhangi bir sorun teşkil etmediği öngörülmektedir. Örneğin; e-maili kontrol etmek, k1sa süreli haber siteleri, e-gazete okuma gibi aktiviteler sayllabilir. Lim (2002) ise web sitesi aktiviteleri ve e-mail aktiviteleri olarak sanal kaytarmayı gruplandırmıştır. Seymour ve Nadasen (2007) göre çalışanlar internet sayesinde bilgi düzeylerini arttırdığını ve böylece örgütün verimliliğine katkı sağladığını öne sürmüştür. Bunun tam aksi olarak da Lim ve Teo (2005) ise sanal kaytarma mesai saatleri içerisinde zaman kaybı olup verimsizliğe yol açtığını savunmuştur. Literatürde çok az da olsa sanal kaytarmanın hem bireye hem de örgüte olumlu yönde etki ettiğine dair pozitif yansımalar 
Süleyman Demirel Üniversitesi Vizyoner Dergisi, Yıl: 2020, Cilt: 11, Sayı: Ek, 29-41.

Süleyman Demirel University Visionary Journal, Year: 2020, Volume: 11, No: Supplement, 29-41.

görülmektedir (Seymour ve Nadasen, 2007: 544; Keklik, Kılıç, Yıldız ve Yıldız, 2015; Carlson, Zivnuska, Harris, Harris ve Carlson, 2016; Vitak vd., 2011: 1752).

Örgütler sanal kaytarmayı engellemek için bir takım önlemler almaktadır. Sanal kaytarmayı engellemeye yönelik alınacak tedbirlerin etkili olabilmesi için çalışanların duyguları, davranışları ve algıları durumsal olarak değerlendirilmelidir. Çalışanlar kuralları ihlal eden kişinin cezalandırıldığını ve büyük sorunlarla karşılaşacağını bilmediği zaman, sanal kaytarma davranışının azalması için izlenen politikaların ve sistemlerin ciddi bir etkisi bulunmamaktadır. Yapılan çalışmalar gösteriyor ki caydırıcı cezaların varlığı ve sıkı takip programı olduğu zaman sanal kaytarma davranışlarında azalma olduğu görülmüştür (Hassan, Reza ve Farkhad, 2015: 97).

Yapılan araştırmalar gösteriyor ki iş ve özel yaşamda teknolojinin payı ve etkisi giderek artmaktadır (Weatherbee, 2010: 36). Bundan dolayı iş yerinde internet kullanımı bilim insanın dikkatini cezbetmeye başlamıştır (Lim ve Chen, 2012: 243). Türkiye'de 2003 yılından itibaren hayata geçen Sağlıkta Dönüşüm Programı ile sağlık alanında birçok hedef belirlenmiş ve birçok değişim gerçekleşmiştir. Bu hedefler arasında sağlık çalışanlarının bilgi ve beceri ile donanmış olması, yüksek motivasyonla hizmet sunmaları, ayrıca karar sürecinde etkili bilgiye erişim için sağlık bilgi sisteminin geliştirilmesi gibi iki önemli hedef yer almaktadır (Filiz, 2017: 34).

$\mathrm{Bu}$ iki hedefinde sağlık kurumlarında teknoloji kullanımının giderek yaygınlık kazanacağını gösteriyor. Teknolojinin artması demek sanal kaytarma davranışlarının da beraberinde artması demektir. Sanal kaytarma davranışları birçok kurumda görüldüğü gibi sağlık kurumlarında da görülmektedir. Sağlık çalışanları sanal kaytarma davranışlarını belirlemeye yönelik literatürde birçok çalışma bulunmaktadır (Morahan-Martin, 2001; Garrett ve Danziger, 2008; Liberman vd., 2011; Doorn, 2011;Köse, Oral ve Türesin, 2012; Özkalp vd., 2012; Akça, 2013; Çavuşoğlu, Palamutçuoğlu ve Palamutçuoğlu 2014; Kaplan ve Çetinkaya, 2014; Ünal vd., 2015; Özdem ve Demir, 2015; Candan ve İnce, 2016; Ulusoy ve Benli, 2017; Bacaksı, Tuna ve Harmanc1, 2018; Demir ve Tan, 2018; Kirtay, 2019).

Tüm sektörlerde olduğu gibi sağlık sektöründe de rekabet giderek artmakta, sağlık harcamaları ciddi boyutlara ulaşmakta ve hastaların bilgi ve beklentileri de artmaktadır. Bu durum hükümetleri sağlık alanına tahsis edilen sınırlı kaynakları verimli ve etkili kullanmaya sevk etmektedir. Birçok ülke bu gidişata ayak uydurmak için sağlık sistemlerinde çeşitli yenilikler gerçekleştirmektedir. Yenilikler genel itibariyle sağlık sistemlerinin hizmet sunumu, organizasyon, yönetim ve insan gücü fonksiyonları üzerinde gerçekleşmektedir. Bu fonksiyonların dördü de önemli olmakla beraber, sağlık kurumları hizmet temelli yapılar olduğu için çalışanların kalitesi büyük önem arz etmektedir (Filiz ve Bardakçı, 2020: 437). Çalışanların kalitesi tüm sistemi etkilemektedir, diğer tüm fonksiyonların verimini belirleyen çalışanların kalitesidir. Sanal kaytarma davranışları çalışanların verimi üzerinde genel olarak olumsuz yönde etki etmektedir. Bu tür çalışmaların sağlık kurumlarında verimi artırmak ve sürdürmek açısından yol gösterici olduğu düşünülmektedir.

Genel olarak veya sağlık sektörüyle ilgili yapılmış birçok sanal kaytarma çalışmasına yukarıda atıf yapıılmıştır. Mevcut çalışmalarda daha çok sanal kaytarma alanları, nedenleri gibi hususlar üzerinde yoğunlaşmış bulunulmaktadır. Sanal kaytarma sürelerine yönelik bir çalışmaya literatür taramasında rastlanmamıştır. Literatürde görülen bu eksikliği gidermek ve esasta sanal kaytarmanın işveren ve kurumlara muhtemel mesai maliyetinin ortaya konulmasına olan ihtiyaç aşikârdır. Bu çalışma, sağlık sektöründe sağlık çalışanlarının kendi ifadeleri üzerinden haftalık mesai süreleri içerisinde gerçekleştirdikleri sanal kaytarma sürelerinin tespitini amaçlamıştır. Böylece işveren ve kurumlara sanal kaytarmanın çalışan maliyetleri açısından yüklediği maliyetin tespitine imkân sağlamak istenmektedir. Ayrıca yeni yapılacak sanal kaytarma çalışmaları için sanal kaytarma sürelerini ölçmeyi de kapsayan yeni bir ölçek oluşturmak ve literatüre bu yönde katkı yapmak hedeflenmiştir.

\section{MATERYAL VE METOD}

\section{1. Örneklem Seçimi}

Araştırmanın evrenini Artvin Devler Hastanesinde ve Arhavi Devlet Hastanesinde çalışmakta olan toplam 326 sağlık çalışanı oluşturmaktadır. Bu sağlık çalışanlarından bir kısmına, nöbet tutuğu veya hafta sonu çalıştığı için normal mesaide olmaması, izinde olması gibi nedenlerle ulaşılamamıştır. 215 sağlık çalışanına anketler elden dağıtılmış, gün içerisinde doldurması istenmiştir. Dağıtılan anketlerden çalışmaya katılmaya gönüllü olan 133 sağlık çalışanından geçerli anket sağlanmıştır. Ulaşılan sağlık çalışanlarının anketleri doldurma oranı \%61 olarak gerçekleşmiştir. Sağlık çalışanlarının yoğun çalışması, anketleri doldurmada gönülsüz olmaları araştırmanın 
Süleyman Demirel Üniversitesi Vizyoner Dergisi, Yıl: 2020, Cilt: 11, Sayı: Ek, 29-41.

Süleyman Demirel University Visionary Journal, Year: 2020, Volume: 11, No: Supplement, 29-41.

örnekleminin sınırlılıklarını oluşturmaktadır. Söz konusu örneklem grubu kolayda örnekleme yöntemiyle belirlenmiştir. Kolayda örnekleme yöntemini seçme nedeni ise diğer örnekleme tekniklerine göre daha kolay, daha ucuz ve hızlı veri toplamaya imkân sağlıyor olmasıdır (Gürbüz ve Şahin, 2014). Kolayda örnekleme yönteminin seçilmesinde diğer neden ise hastanedeki sağlık çalışanının ankete maksimum düzeyde katılımını sağlamak için tercih edilmiştir.

\section{2. Ölçeğin Geliştirilmesi, Geçerlilik ve Güvenirlik}

Araştırma, sağlık çalışanlarının çalışma ortamlarında, işleri dışında, kişisel ihtiyaçları doğrultusunda iletişim teknolojilerini kullanarak gerçekleştirdikleri sanal kaytarma faaliyetlerini ve sürelerini belirlemeye çalışmaktadır. Tanımlayıcı bir çalışma olup, nicel yöntemle yapılmıştır. Araştırma'da beşli likert anket tekniği ile oluşturulmuş bir ölçek kullanılmıştır. Araştırmada veriler soru formu demografik bilgiler ve sanal kaytarma ölçeği olmak üzere iki kısımdan oluşmaktadır.

Sosyodemografik Bilgiler: Katılımcıların kişisel özelliklerini belirlemek üzere 10 sorudan oluşan bir kısımdır. Sağlık çalışanların meslek, eğitim düzeyi, cinsiyet, yaş, gelir, çalışma yılı, evde internet bağlantısının olup olmaması cep telefonunda internet paketi olup olmaması, işinin internet gerektirip gerektirmemesi ve günlük ortalama internette bulunma süresi gibi sorular yöneltilmiştir.

Sanal Kaytarma Ölçeği: Bu ölçek başlangıçta 20 soru olarak tasarlanmıştır. Soruların 8’i Lim vd., (2002) (Tablo 1'deki 2,4,8,14,17,18,19 nolu ifadeler) tarafından geliştirilen ölçekten yararlanarak Türkçeye uyarlanmıştır. Soruların geri kalanı ise araştırmacılar tarafından literatür taraması ve iş ortamlarında gözlemler yapılarak oluşturulmuştur. Elde edilen soru seti hakkında sağlık yönetimi ve iletişim alanından yedi uzmanın görüşleri alınarak, soruların ifade biçimleri gözden geçirilmiştir. Ölçek araştırma evrenindeki 30 sağlık çalışanına uygulanmış, soruların anlaşılmasında bir sorun görülmeyince, ölçeğin uygulanmasına devam edilmiştir. Sanal kaytarma ölçeği 5'li derecelendirilmiş ölçek tarzında olup, sağlık çalışanlarının çalışma saatleri içerisinde iş dışı bilgi teknolojileri ve sanal uygulamalarla geçirdikleri süreyi 0-15 dakika, 16-30 dakika, 31-60 dakika, 61-120 dakika ve 120 dakikadan fazla şeklinde katlamalı olarak tanımlamaktadır. İnternette geçirilen süre artıkça sanal kaytarma düzeyi de artmakta olduğunu göstermektedir.

Sanal kaytarma ölçeğinin geçerliliği ve güvenirliğinin analizinde SPSS programı kullanılmıştır. Sanal kaytarma ölçeğinin maddelerinin yapı geçerliliğini sağlamak için faktör analizi yapılmıştır. Geçerlilik bir test ya da ölçeğin ölçmek istenilen şeyi ölçme derecesidir (Coşkun, Altunışık ve Yıldırım, 2017). Örneklem sayısının yeterli olup olmadığını anlamak için Kaiser-Meyer-Olkin (KMO) testi yapılmış olup 0,861 olduğu görülmüştür. KMO değeri 1 'e yaklaştıkça çalışmada kullanılan örneklem büyüklüğünün mükemmele ulaşmakta olduğu ve bu değerin 0,80 çok iyi ve 0,90 mükemmel olarak kabul edilmektedir (Karagöz, 2017). Ayrıca, maddeler arası korelasyonun anlamlı olup olmadığını öğrenmek için Barlett küresellik testi sonuçlarına bakılmış ve (Approx. Chi-Square: 961,814/ df: 105/ sig: 0.000) 0.001 düzeyinde anlamlı olduğu görülmüştür. Maddeleri boyutlandırmak için "principal components" metodu ile "Direct Oblimin" döndürme işlemi uygulanmıştır. Ölçek maddelerinin 0.40 ve üzeri faktör yükleri alması yüksek yükler olarak tanımlanır (Hair, Sarstedt, Ringle ve Mena, 2010). Yirmi ifadeden oluşan sanal kaytarma ölçeğinden beş ifade faktör yükleri yetersiz olduğu için çıkartılmış ve ölçek on beş ifadeden oluşmuştur. Buna göre sadece bir ifade 0.381 ile yüklenmiş olup, kalan on dört ifade 0.40 ve üzeri yükler ile yüklenmiştir. Ölçek maddelerinin yüksek yük taşıdığı söylenebilir. Sanal Kaytarma ölçeği farklı boyutlara bölünmeden tek faktör altında toplanmıştır. Ölçek maddelerinin yükleri Tablo 1'de verilmiştir. Sanal Kaytarma Ölçeğini oluşturan tek faktör toplam varyansın \%40.758'ini açıklamaktadır. Ölçeğin güvenirlik analizi için Cronbach's Alpha katsayısına bakılmış ve on beş ifadeden oluşan tek faktör için bu değerin 0.891 olduğu görülmüştür. Sanal kaytarma ölçeğinin Cronbach $\alpha$ katsayısının 0,60’tan büyük olduğu ve dolayısıyla yüksek düzeyde güvenirliğe sahip olduğu söylenebilir (Özdamar, 1999). 
Süleyman Demirel Üniversitesi Vizyoner Dergisi, Yıl: 2020, Cilt: 11, Sayı: Ek, 29-41.

Süleyman Demirel University Visionary Journal, Year: 2020, Volume: 11, No: Supplement, 29-41.

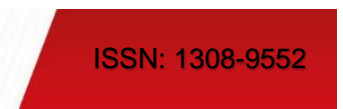

Tablo 1. Sanal Kaytarma Ölçeğinin Maddelerinin Faktör Yükleri Tablosu

\begin{tabular}{lc}
\hline İfade & Faktör Yükü \\
\hline 1.Kişisel sesli ve görüntülü haberleşmelerimi yaparım &, 673 \\
2.Alış veriş sitelerini dolaşır fiyat araştırması veya alış veriş yaparım &, 462 \\
3.E-kitap okurum &, 632 \\
4.Haber sitelerinde dolaşırım &, 690 \\
5.Gazete okurum &, 694 \\
8.Dizi, film, maç vb. programları izlerim &, 679 \\
9.Yazılım programları indiririm &, 586 \\
10.Bankacılık işlemleri yaparım &, 731 \\
13.Kişisel hobilerimle ilgili bilgi edinirim &, 381 \\
14.İşarama sitelerini incelerim &, 581 \\
15.Müzik dinlerim &, 645 \\
16.Forum sitelerine katılır, görüşmeler yapar, mesajlaşırım &, 695 \\
17.Bilgisayar oyunları oynarım &, 714 \\
18.Online eğlence ve kumar sitelerine takılırım &, 635 \\
19.Kişisel sosyal medya araçlarımı (facebook, instagram, twitter vb.) kullanırım &, 675 \\
\hline
\end{tabular}

\subsection{Araştırmanın Etik Yönü ve Verilen Toplanması}

Araştırmada kullanılan veri toplama aracı, bilimsel araştırma ve yayın etiği ilkelerine uygunluk yönünden Artvin Çoruh Üniversitesi Bilimsel Araştırma ve Yayın Etiği Kurulu tarafından incelenmiş, kurulun 05.12.2018 tarihli ve E.20010 sayılı kararıyla etik yönden uygun olduğu belirlenmiştir. Etik kurul onayı alınan anketin uygulanması için ayrıca uygulamanın yapıldığı hastaneler içinde İl Sağlık Müdürlüğünden 07.02.2019 tarihli ve 96812711-000-509 sayılı yazı ile resmi izin alınmıştır. Ölçek, çalışma grubunu oluşturan 133 sağlık çalışanı ile yüz yüze anket yoluyla 11.02.2019-28.02.2019 tarihleri arasında uygulanmış ve araştırma verileri elde edilmiştir.

\subsection{Kullanılan İstatistiksel Yöntemler}

Araştırmaya katılan çalışanların demografik değişkenleri ve sanal kaytarma ölçeği verileri frekans tabloları aracılığıyla açıklanmıştır. Her ifadeyle (maddeyle) ve ortalamayla ilgili sanal kaytarma sürelerinin hesaplanmasında gruplanmış (sınıflandırılmış) seriler için aritmetik ortalama hesaplanması tekniği kullanılmıştır. Verilerin analizinde SPSS programı kullanılmıştır. Araştırma verilerin analizleri 0,95 güven aralığında yapıllmıştır. Verilerin istatistiksel analizinde uygulanacak testleri belirlemek için SPSS programında ölçeğin Skewness $(0,368)$ ve Kurtosis $(-0,884)$ değerlerine bakılmış, değerler -1 ile 1 arasında olduğu görülmüştür. Bu testlerde basıklık ve çarpıklık (Skewness ve Kurtosis) değerlerine bakılırken Tabashnick ve Fidell'e göre (2013) -1,5 ile +1,5 olması halinde, George ve Mallery' e göre (2016) de -2,0 ile +2,0 olması halinde homojen dağılım ya da normal dağılım olduğu anlaşılmıştır. Bu nedenle demografik değişkenlerin ölçek üzerindeki ayırt edici etkisini belirlemek için parametrik testlerden t ve ANOVO testleri kullanılmıştır.

\section{BULGULAR}

Araştırma formunda demografik ve mesleki bilgilere yer verilen değişkenlere ait elde edilen frekans ve yüzde değerleri Tablo 2'deki gibidir. 
Süleyman Demirel Üniversitesi Vizyoner Dergisi, Yıl: 2020, Cilt: 11, Sayı: Ek, 29-41.

Süleyman Demirel University Visionary Journal, Year: 2020, Volume: 11, No: Supplement, 29-41.

Tablo 2. Demografik Değişkenlere Ait Frekans Tablosu

\begin{tabular}{|c|c|c|c|c|c|}
\hline Değişken & $\mathbf{N}$ & $\%$ & Değişken & $\mathbf{N}$ & $\%$ \\
\hline 1.Meslek Grubu & & & 6.Toplam Çalışma yılı & & \\
\hline Hekim & 16 & 12,0 & $1-5$ y1l aras 1 & 46 & 34,6 \\
\hline Hemşire-Ebe-Sağlık memuru & 23 & 17,3 & $6-10$ y1l aras1 & 45 & 33,8 \\
\hline Sağlık teknisyeni/teknikeri & 23 & 17,3 & $11-15$ y1l aras 1 & 23 & 17,3 \\
\hline Tibbi sekreter-Güvenlik & 38 & 28,6 & $21+y_{1} 1$ & 19 & 14,3 \\
\hline İdari personel & 22 & 16,5 & 7.Evinizde internet bağlantısı var mı? & & \\
\hline Diğer & 11 & 8,3 & Evet & 122 & 91,7 \\
\hline 2.Eğitim düzeyi & & & Hayır & 11 & 8,3 \\
\hline Lise & 34 & 25,6 & 8.Cep telefonunuzda internet paketiniz var mı? & & \\
\hline Önlisans & 49 & 36,8 & Evet & 132 & 99,2 \\
\hline Lisans & 38 & 28,6 & Hayır & 1 & 0,8 \\
\hline Lisansüstü & 12 & 9,0 & 9. İşiniz interneti kullanmanızı gerektiriyor mu? & & \\
\hline 3.Cinsiyet & & & Evet & 121 & 91,0 \\
\hline Kadın & 71 & 53,4 & Hayır & 12 & 9,0 \\
\hline Erkek & 62 & 46,6 & 10.Günlük ortalama internette bulunma süreniz ne kad & ardır? & \\
\hline 4.Yaşınız & & & 0-60 dakika aras 1 & 19 & 14,3 \\
\hline 20-34 yaş arası & 64 & 48,1 & $60-120$ dakika arası & 29 & 21,8 \\
\hline $35-49$ yaş arası & 57 & 42,9 & $120-180$ dakika aras 1 & 28 & 21,1 \\
\hline $50+$ yaş & 12 & 9,0 & 180-240 dakika arası & 13 & 9,8 \\
\hline 5.Aylık ortalama gelir & & & 240-300 dakika arası & 7 & 5,3 \\
\hline 1-1999 TL aras1 & 2 & 1,5 & 300+ dakika & 37 & 27,8 \\
\hline 2000-3999 TL aras1 & 93 & 69,9 & \multicolumn{3}{|c|}{ Katılımcıların Günlük Toplam İnternet Kullanma Süresi:27.005 dk } \\
\hline 4000-5999 TL aras1 & 28 & 21,1 & \multirow{2}{*}{\multicolumn{3}{|c|}{ Kişi başı Ortalama Günlük İnternet Kullanma Süresi: 203 dk }} \\
\hline $6000+\mathrm{TL}$ & 10 & 7,5 & & & \\
\hline
\end{tabular}

Tablo 2'deki verilere göre; çalışanların meslek gruplarına dağılımının orantılı olduğu anlaşılmaktadır. Çalışanlar ağırlıklı olarak önlisans, lisans ve lise mezunu kişilerdir. Araştırmaya katılan çalışanların demografik özelliklerine göre cinsiyetleri beklendiği gibi kadın ağırlıklı, genç, beş yıldan az çalışma süresine sahip ve gelir düzeyleri dört bin TL'den az olan bireylerden oluştuğu görülmüştür. Çalışanların \%91'inin evinde, tamamına yakının cep telefonunda internet bulunmakta ve \%91'inin işi internet kullanmayı gerektirmektedir. Sağlık çalışanlarının kendi beyanlarına göre günde ortalama $203 \mathrm{dk}$ internet kullanımına süre ayırdıkları ve buna göre hesaplandığında haftalık (7 gün) kişi başı internette geçirilen süre $1421 \mathrm{dk}$ olduğu görülmüştür.

Sanal kaytarma ölçeği içerisinde sanal kaytarma konuları ve her bir sanal kaytarma faaliyeti için ortalama harcanan zamanı gösteren frekans dağılımı Tablo 3'de verilmiştir. 
Süleyman Demirel Üniversitesi Vizyoner Dergisi, Yıl: 2020, Cilt: 11, Sayı: Ek, 29-41.

Süleyman Demirel University Visionary Journal, Year: 2020, Volume: 11, No: Supplement, 29-41.

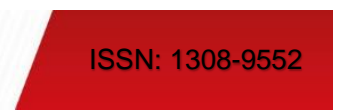

Tablo 3. Sanal Kaytarma Ölçeği Frekans Tablosu

\begin{tabular}{|c|c|c|c|c|c|c|c|c|c|c|c|}
\hline \multirow{3}{*}{ Sanal Kaytarma Faaliyetleri } & \multicolumn{10}{|c|}{$\begin{array}{l}\text { Haftalık Mesai Süresi İçerisindeki (2400 dk) Sanal Kaytarma } \\
\text { Süreleri }\end{array}$} & \multirow{3}{*}{$\begin{array}{c}\text { Toplam ve } \\
\text { Kişi başı } \\
\text { Ortalama } \\
\text { Süre(dk) } \\
\end{array}$} \\
\hline & \multicolumn{2}{|c|}{$0-15 \mathrm{dk}$} & \multicolumn{2}{|c|}{$16-30 \mathrm{dk}$} & \multicolumn{2}{|c|}{$31-60 \mathrm{dk}$} & \multicolumn{2}{|c|}{$61-120 \mathrm{dk}$} & \multicolumn{2}{|c|}{$121 \mathrm{dk}$ ve üzeri } & \\
\hline & $\mathbf{n}$ & $\%$ & $\mathbf{n}$ & $\%$ & $\mathbf{n}$ & $\%$ & $\mathbf{n}$ & $\%$ & $\mathbf{n}$ & $\%$ & \\
\hline $\begin{array}{l}\text { 1. Kişisel sesli ve görüntülü } \\
\text { haberleşmelerimi yaparım }\end{array}$ & 64 & 48,1 & 42 & 31,6 & 17 & 12,8 & 2 & 1,5 & 8 & 6,0 & $3882-29$ \\
\hline $\begin{array}{l}\text { 2.Alış veriş sitelerini dolaşır fiyat } \\
\text { araştırması veya alış veriş yaparım }\end{array}$ & 68 & 51,1 & 47 & 35,3 & 13 & 9,8 & 2 & 1,5 & 3 & 2,3 & $2945-22$ \\
\hline 3.E-kitap okurum & 64 & 48,1 & 46 & 34,6 & 16 & 12,0 & 3 & 2,3 & 4 & 3,0 & $3299-25$ \\
\hline 4.Haber sitelerinde dolaşırım & 39 & 29,3 & 49 & 36,8 & 31 & 23,3 & 7 & 5,3 & 7 & 5,3 & $4762-36$ \\
\hline 5.Gazete okurum & 55 & 41,4 & 47 & 35,3 & 21 & 15,8 & 5 & 3,8 & 5 & 3,8 & $3842-29$ \\
\hline 8.Dizi, film, maç vb. programları izlerim & 48 & 36,1 & 35 & 26,3 & 16 & 12,0 & 13 & 9,8 & 21 & 15,8 & $6888-52$ \\
\hline 9.Yazılım programları indiririm & 50 & 37,6 & 47 & 35,3 & 28 & 21,1 & 2 & 1,5 & 6 & 4,5 & $4031-30$ \\
\hline 10.Bankacıllk işlemleri yaparım & 61 & 45,9 & 45 & 33,8 & 20 & 15,0 & 2 & 1,5 & 5 & 3,8 & $3525-27$ \\
\hline $\begin{array}{l}\text { 13.Kişisel hobilerimle ilgili bilgi } \\
\text { edinirim }\end{array}$ & 61 & 45,9 & 40 & 30,1 & 24 & 18,0 & 6 & 4,5 & 2 & 1,5 & $3418-26$ \\
\hline 14.İş arama sitelerini incelerim & 73 & 54,9 & 47 & 35,3 & 10 & 7,5 & - & - & 3 & 2,3 & $2665-20$ \\
\hline 15.Müzik dinlerim & 52 & 39,1 & 39 & 29,3 & 23 & 17,3 & 9 & 6,8 & 10 & 7,5 & $4990-38$ \\
\hline $\begin{array}{l}\text { 16.Forum sitelerine katılır, } \\
\text { görüşmeler yapar, mesajlaşırım }\end{array}$ & 77 & 57,9 & 41 & 30,8 & 7 & 5,3 & 3 & 2,3 & 5 & 3,8 & $3054-23$ \\
\hline 17.Bilgisayar oyunları oynarım & 87 & 65,4 & 32 & 24,1 & 7 & 5,3 & 2 & 1,5 & 5 & 3,8 & $2836-21$ \\
\hline $\begin{array}{l}\text { 18.Online eğlence ve kumar } \\
\text { sitelerine takılırım }\end{array}$ & 81 & 60,9 & 43 & 32,3 & 2 & 1,5 & 3 & 2,3 & 4 & 3,0 & $2722-20$ \\
\hline $\begin{array}{l}\text { 19.Kişisel sosyal medya araçlarımı } \\
\text { (facebook, instagram, twitter vb.) } \\
\text { kullanırım }\end{array}$ & 51 & 38,3 & 29 & 21,8 & 18 & 13,5 & 12 & 9,0 & 23 & 17,3 & $7135-54$ \\
\hline Ortalama kişi sayısı ve Oranı & 62 & 46,6 & 42 & 31,5 & 17 & 12,7 & 5 & 3,7 & 7 & 5,2 & \\
\hline Ortalama Süre (ortalama dk) & & & & & & & & & & & $452 \mathrm{dk}$ \\
\hline
\end{tabular}

Tablo 3 süreler açısından incelendiğinde; sağlık çalışanlarının ortalama \%46,6’sı 15 dk, \%31,5'i 30 dk, \%12,7'si $60 \mathrm{dk}, \% 3,7$ 'si $120 \mathrm{dk}$ ve \%5,2'si $120 \mathrm{dk}$ 'dan daha fazla sanal kaytarma yapmaktadır. Bu rakamlar üzerinden yapılan bir ortalama hesabına göre her bir sağlık çalışanı haftada ortalama $452 \mathrm{dk}$ (7,5 saat) mesai süresini sanal kaytarma yaparak geçirmektedir. Bu süre yaklaşık haftalık mesaide bir güne tekabül etmekte ve mesai süresinin yaklaşık \%20’sini kapsamaktadır.

15 dakika sanal kaytarma yapanlarda bilgisayar ve sanal oyunları oynamanın, 30 dakika sanal kaytarma yapanlarda haber sitelerinde gezinme ve gazete okumanın, 60 dakika sanal kaytarma yapanlarda haber sitelerinde dolanma, yazılım programı indirme ve kişisel hobilerle ilgili araştırma yapanların, 120 dakika ve 120 dakikadan daha fazla sanal kaytarma yapanlarda dizi, film, maç izleme, müzik dinleme ve kişisel sosyal medyayla oyalanmanın ön plana çıktığı tespit edilmiştir.

Sanal kaytarma konularına ayrılan zaman açısından veriler incelendiğinde kişisel sosyal medya araçlarını kullanma $54 \mathrm{dk}$ ile ilk sırayı almaktadır. Dizi, film, maç izleme $52 \mathrm{dk}$ ve müzik dinlenme $38 \mathrm{dk}$ ile sıralamayı takip etmektedir.

Sağlık çalışanlarının \%46,6'sı 15 dk 'ya kadar; \%31,5'i 30 dk 'ya kadar; \%12,7'si 60 dk 'ya kadar; \%3,7'si 120 dk 'ya kadar ve \%5,2'si 120 dg'dan fazla haftalık mesailerinde sanal kaytarma yapmaktadır. Mesai süresi içerisinde bir saatten daha fazla sanal kaytarma yapan \%8,9'luk bir çalışan kitlesi bulunmaktadır.

Sağlık çalışanlarının demografik ve mesleki özelliklere göre sanal kaytarma davranışı gösterme durumu incelendiğinde cinsiyet açısından önemli bir farklılık olduğu tespit edilmiştir. Bağımsız değişkenlerden meslek, eğitim, yaş ve gelir değişkenlerinde birer ifadede ve çalışma yılı değişkeninde iki ifadede anlamlı farklılık bulunmuştur. Evde, cep telefonunda ve iş yerinde internet bulunma oranları \% 00 'nın üzerinde olduğu ve interneti olmayan sağlık çalışanı sayısı yetersiz bulunduğu için bu değişkenlerde fark testleri yapılmamıştır.

Meslek değişkeninde idari personel daha fazla "yazılım programı” indirmektedir (F: 2,372 ve P: 0,043). Eğitim değişkeninde yine lise mezunları -ki daha çok idari personeldir- daha fazla "yazılım programı" indirmektedir (F: 
Süleyman Demirel Üniversitesi Vizyoner Dergisi, Yıl: 2020, Cilt: 11, Sayı: Ek, 29-41.

Süleyman Demirel University Visionary Journal, Year: 2020, Volume: 11, No: Supplement, 29-41.

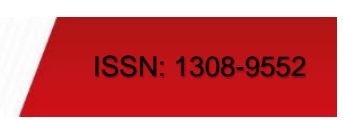

5,887 ve P: 0,001). Yaş değişkeninde 50 yaş üzeri "Kişisel sosyal medya araçlarını (facebook, instagram, twitter vb.)" daha az kullanmaktadır (F: 7,367 ve P: 0,001). Gelir değişkeninde geliri altı bin liranın üzerinde olanlar daha fazla "haber sitelerinde" dolanmaktadır (F: 3,264 ve P: 0,024). Çalışma yılı değişkeninde ise çalışma süresi 21 ve daha fazla olan çalışanlar daha az "E-kitap" okumakta (F: 3,795 ve P: 0,012) ve "Kişisel sosyal medya araçlarını (facebook, instagram, twitter vb.)" daha az kullanmaktadır (F: 4,746 ve P: 0,004).

Sağlık çalışanlarının sanal kaytarma faaliyet ve süreleri üzerinde meslekleri, eğitimleri, yaşları, gelirleri ve çalışma yıllarının etkili olmadığı yapılan ANOVA testleri sonucunda anlaşılmıştır. Sağlık çalışanlarının demografik özelliklerinden cinsiyet farklılığının ise önemli ölçüde sanal kaytarma davranışını farklılaştırdığ görülmüştür. Cinsiyete göre farklılaşma aşağıda açıklanmıştır. Sağlık çalışanlarının nerdeyse tamamına yakının evinde, cep telefonunda internet bulunduğu ve işlerinde internet kullandıkları için internet kullanma durumlarının sanal kaytarma davranışları üzerindeki etkisi araştırılmamıştır.

Sağlık çalışanlarının cinsiyeti açısından sanal kaytarma faaliyetlerinin on tanesinde anlamlı farklılık bulunmaktadır. Anlamlı farklılık bulunmayan "telefonla görüşme", "alış-veriş sitelerini dolanma", "kişisel hobiler hakkında bilgi edinme", "müzik dinleme" ve "kişisel sosyal medya araçlarını kullanma" faaliyetlerinde süre açısından kadın-erkek ayrımı olmadığı anlaşılmıştır. Diğer bütün sanal kaytarma faaliyetlerinde erkekler kadınlardan daha fazla bir süre sanal kaytarma yapmaktadırlar. Cinsiyetle ilgili sanal kaytarma verileri Tablo 4'de verilmiştir.

Tablo 4. Sağlık Çalışanlarının Cinsiyete Göre Sanal Kaytarma Faaliyetleri

\begin{tabular}{|c|c|c|c|c|c|c|}
\hline SN & Cinsiyet & $\mathbf{N}$ & Ortalama & Std.Sapma & $\mathbf{T}$ & P(Sig.2-tailed) \\
\hline \multirow{2}{*}{1} & Kadın & 71 & 1,8310 & ,97080 & \multirow{2}{*}{,- 294} & \multirow{2}{*}{,769 } \\
\hline & Erkek & 62 & 1,8871 & 1,22949 & & \\
\hline \multirow{2}{*}{2} & Kadın & 71 & 1,6901 & 85509 & \multirow{2}{*}{,083 } & \multirow{2}{*}{,934 } \\
\hline & Erkek & 62 & 1,6774 & ,91927 & & \\
\hline \multirow{2}{*}{3} & Kadın & 71 & 1,5352 & 69346 & \multirow{2}{*}{$-3,186$} & \multirow{2}{*}{,002 } \\
\hline & Erkek & 62 & 2,0484 & 1,13697 & & \\
\hline \multirow{2}{*}{4} & Kadın & 71 & 1,9859 & ,87002 & \multirow{2}{*}{$-2,518$} & \multirow{2}{*}{,013 } \\
\hline & Erkek & 62 & 2,4516 & 1,25028 & & \\
\hline \multirow{2}{*}{5} & Kadın & 71 & 1,7606 & ,86956 & \multirow{2}{*}{$-2,081$} & \multirow{2}{*}{,039 } \\
\hline & Erkek & 62 & 2,1290 & 1,16624 & & \\
\hline \multirow{2}{*}{8} & Kadın & 71 & 2,1268 & 1,28652 & \multirow{2}{*}{$-2,610$} & \multirow{2}{*}{010} \\
\hline & Erkek & 62 & 2,7742 & 1,57250 & & \\
\hline \multirow{2}{*}{9} & Kadın & 71 & 1,7606 & ,74575 & \multirow{2}{*}{$-2,952$} & \multirow{2}{*}{,004 } \\
\hline & Erkek & 62 & 2,2742 & 1,23035 & & \\
\hline \multirow{2}{*}{10} & Kadın & 71 & 1,5915 & ,80316 & \multirow{2}{*}{$-3,116$} & \multirow{2}{*}{,002 } \\
\hline & Erkek & 62 & 2,1129 & 1,11774 & & \\
\hline \multirow{2}{*}{13} & Kadın & 71 & 1,7746 & ,89757 & \multirow{2}{*}{$-1,050$} & \multirow{2}{*}{,296 } \\
\hline & Erkek & 62 & 1,9516 & 1,04689 & & \\
\hline \multirow{2}{*}{14} & Kadın & 71 & 1,4366 & ,60314 & \multirow{2}{*}{$-2,421$} & \multirow{2}{*}{,017 } \\
\hline & Erkek & 62 & 1,7742 & ,98212 & & \\
\hline 15 & Kadın & 71 & 2,0423 & 1,10112 & 1013 & 313 \\
\hline & Erkek & 62 & 2,2581 & 1,35423 & $-1,013$ & ,313 \\
\hline & Kadın & 71 & 1,4789 & ,73405 & & \\
\hline 16 & Erkek & 62 & 1,8065 & 1,15714 & $-1,974$ & ,050 \\
\hline 17 & Kadın & 71 & 1,2535 & ,43812 & 3014 & 000 \\
\hline 17 & Erkek & 62 & 1,8710 & 1,23453 & $-3,914$ & , \\
\hline & Kadın & 71 & 1,3521 & ,53715 & & \\
\hline 18 & Erkek & 62 & 1,7581 & 1,12622 & $-2,706$ & ,008 \\
\hline 10 & Kadın & 71 & 2,2817 & 1,39574 & 1300 & 164 \\
\hline 19 & Erkek & 62 & 2,6452 & 1,60017 & $-1,399$ & 164 \\
\hline
\end{tabular}


Süleyman Demirel Üniversitesi Vizyoner Dergisi, Yıl: 2020, Cilt: 11, Sayı: Ek, 29-41.

Süleyman Demirel University Visionary Journal, Year: 2020, Volume: 11, No: Supplement, 29-41.

Tablo 4 incelendiğinde, sağlık çalışanlarının sanal kaytarma faaliyetlerinden "E-kitap okurum”, "Haber sitelerinde dolaşırım", "Gazete okurum", "Dizi, film, maç vb. programları izlerim", "Yazılım programları indiririm", "Bankacılık işlemleri yaparım", "İş arama sitelerini incelerim", "Forum sitelerine katılır, görüşmeler yapar, mesajlaşırım", "Bilgisayar oyunları oynarım" ve "Online eğlence ve kumar sitelerine takılırım" faaliyetlerinde erkekler kadınlardan daha fazla süre harcamaktadır.

\section{TARTIŞMA}

Sağlık çalışanlarının hastane ortamında mesai saatleri içerisinde iletişim teknolojilerini kullanma nedenleri analiz etmek ve belirlenen değişkenlere göre kullanımın farklılık gösterip göstermediğini belirlemek için yapılan bu çalışmada önemli bulgulara ulaşılmıştır. Elde edilen bulgular literatürdeki benzer çalışmalarla karşılaştırılarak tartışılacaktır.

Sanal kaytarma konularına ayrılan zamanın kişisel sosyal medya araçlarını kullanma 54 dk ile ilk sırayı almaktadır. Dizi, film, maç izleme $52 \mathrm{dk}$ ve müzik dinlenme $38 \mathrm{dk}$ ile sıralamayı takip etmektedir. Bacaksız vd., (2018) yaptıkları çalışmada sanal kaytarma davranışı olarak çalışanların en çok haber sitelerini ziyaret etme, internet üzerinden alışveriş yapma veya bankacılık işlemleri yapma gibi davranışlar sergiledikleri görülmüştür. Köse vd., (2012) yaptıkları çalışmada çalışanların hemen hemen hepsinin internetten gazete okumak, e-mail almak ve göndermek gibi davranışlar sergiledikleri görülmüştür. Özkalp vd., (2012) çalışmasında katılımcıların büyük çoğunluğunun akademisyen olmasından dolayı internet kullanma nedeni olarak en başta akademik çalışmalar gelmekte olup, ikinci sırada ise gazete okuma ve haber takip etme olarak görülmüştür. Kırtay (2019) çalışanların en çok yaptığı sanal kaytarma davranışı sırasıyla, haber sitelerini ziyaret etmek, kişisel e-maillerini okumakcevaplamak ve online alışveriş sitelerinden kişisel alışveriş yapmak olduğu görülmüştür. Genel olarak sanal kaytarma davranışlarında en çok haber, maç, dizi, film izleme vb. faaliyetlerinin öne çıkması beklenilen bir durumdur. Nitekim bu çalışmada da literatürde benzer bulgular elde edilmiştir.

Çalışmada eğitim değişkeni açısından bakıldığı zaman lise mezunlarının daha fazla "yazılım programı" indirdiği görülmüştür. Garrett ve Danziger (2008), Çavuşoğlu vd., 2014) yaptıkları çalışmada eğitim düzeyi arttıkça sanal kaytarma düzeyinin de artığı görülmüştür. Kaplan ve Çetinkaya (2014) yaptıkları çalışmada eğitim düzeyi artıkça önemsiz olarak kabul edilen sanal kaytarma davranışlarının arttığı ve eğitim düzeyinin her düzeyinde önemli sanal kaytarma davranışları arasında negatif yönlü bir ilişki görülmüştür. Demir ve Tan (2018) yaptıkları çalışmada eğitim grupları arasında en fazla sanal kaytarma davranışında bulunan mezunların üniversite mezunları olduğu ve daha sonra lise mezunları olduğu görülmüştür. Ulusoy ve Benli (2017) ve Kırtay (2019) çalışmalarında eğitim düzeyi ile sanal kaytarma davranışları arasında anlamlı bir farklılık görülmemiştir. Çalışmada lise mezunları genel itibariyle idari birimlerde çalıştığı görülmüştür. Bu durum vakit açısından daha müsait olan lise mezunlarının daha çok sanal kaytarma davranışları sergilemeleri beklenilen bir durumdur.

Çalışmada yaş değişkeninde 50 yaş üzeri çalışanların "Kişisel sosyal medya araçlarını (facebook, instagram, twitter vb.)" diğer yaş gruplarına göre daha az kullandığı görülmüştür. Çavuşoğlu ve ark.,(2014) yaptıkları çalışmada genel olarak yaş düzeyi arttıkça sanal kaytarma düzeyinin de arttığı görülmüştür. Çalışmada özellikle 51 yaş ve üzeri çalışanların zarar verici sanal kaytarma davranışlarını diğer yaş gruplarına nispeten daha çok sergiledikleri görülmüştür. Ayrıca çalışmada 26-30 yaş arası çalışanların ciddi sanal kaytarma davranışlarında bulunan grup olarak görülmüştür. Ulusoy ve Benli (2014) çalışmalarında 30-39 yaş arası grubun diğer yaş grubuna göre daha fazla sanal kaytarma davranışları sergiledikleri görülmüştür. Demir ve Tan (2018) yaptıkları çalışmada yaş grupları arasında en büyük grubunun daha fazla sanal kaytarma davranışları (öğrenme ve sosyal amaçlı) sergiledikleri görülmüştür. Restubog vd., (2011) yaptıkları çalışmada benzer sonucu elde etmiştir. Liberman vd.,(2011), Bacaksız vd., (2018) yaptıkları çalışmada 30 yaş ve altı çalışanların diğer yaş gruplarına göre daha fazla sanal kaytarma davranışları sergiledikleri görülmüştür. Doorn (2011) çalışmasında yaş ilerledikçe zararlı(kumar sitelerini ziyaret, bahis oyunları vb.) sanal kaytarma davranışlarının azaldığını ve gençlerin zararlı sanal kaytarma davranışlarını yapmaya daha meyilli olduğu sonucuna ulaşmıştır. Özkalp vd., (2012), Kaplan ve Çetinkaya (2014), Candan ve İnce (2016) ve Kırtay (2019) yaptıkları çalışmada yaş grupları ile sanal kaytarma davranışları arsında anlamlı bir farklılık görülmemiştir. Çalışmada 50 yaş ve üzeri çalışanların sosyal medya araçlarını diğer gruplara göre daha az kullanmaları öngörülebilen bir davranıştır. Literatürdeki bulgularla paralel bir bulgudur. 
Süleyman Demirel Üniversitesi Vizyoner Dergisi, Yıl: 2020, Cilt: 11, Sayı: Ek, 29-41.

Süleyman Demirel University Visionary Journal, Year: 2020, Volume: 11, No: Supplement, 29-41.

Çalışma yılı değişkeni açısından bakıldı̆̆ı zaman çalışma süresi 21 ve daha fazla olan çalışanlar daha az "E-kitap" okumakta ve "Kişisel sosyal medya araçlarını (facebook, instagram, twitter vb.)" daha az kullanmaktadır. Çavuşoğlu vd., (2014) yaptıkları çalışmada görev süresi arttıkça sanal kaytarma düzeyinin de arttığı görülmüştür. Ünal vd., (2015), Ulusoy ve Benli (2017) çalışmalarında çalışma süresi azaldıkça sanal kaytarma düzeyinin arttığı görülmüştür. Özdem ve Demir (2015), Bacaksız vd., (2018) yaptıkları çalışmada sanal kaytarma davranışlarının çalışma süresi 5 yıl ve daha az olan çalışanlarda daha fazla olduğu görülmüşsür. Akça (2013) çalışma yılı artıkça kişisel gelişim amaçlı sanal kaytarma davranışlarının arttığı görülmüştür. Candan ve İnce (2016) çalışanların çalışma süresi arttıkça sanal kaytarma davranışlarında azalma olduğu görülmüştür. Kaplan ve Çetinkaya (2014) yaptıkları çalışmada sanal kaytarma davranışları ile çalışma süresi arasında anlamlı bir ilişki görülmemiştir.

Çalışmada cinsiyet açısından süre olarak sanal kaytarma davranışlarında anlamlı bir fark bulunmazken (telefonla görüşme, alış veriş sitelerini dolanma, kişisel hobiler hakkında bilgi edinme, müzik dinleme ve kişisel sosyal medya araçlarını kullanma), bir kısmında erkeklerin kadınlara göre daha fazla (E-kitap okurum, Haber sitelerinde dolaşırım, Gazete okurum, Dizi, film, maç vb. programları izlerim, Yazılım programları indiririm, Bankacılık işlemleri yaparım, İş arama sitelerini incelerim, Forum sitelerine katılır, görüşmeler yapar, mesajlaşırım, Bilgisayar oyunları oynarım ve Online eğlence ve kumar sitelerine takılırım), davranış sergiledikleri görülmüştür. Demir ve Tan (2018) yaptıkları çalışmada erkeklerin kadınlara göre daha fazla öğrenme ve sosyal amaçlı sanal kaytarma davranışları (sosyal medyada paylaşımda bulunma, sohbet etme, sanal toplulukları/forumları ziyaret etme, gazete, dergi vb. haberlere yorum yapma, e-mailleri kontrol etme) sergiledikleri görülmüştür. Doorn (2011) ve Morahan-Martin (2001)'de çalışmalarında erkeklerin kadınlara göre daha fazla sanal kaytarma davranışlarında bulundukları görülmüştür. Doorn (2011) çalışmasında erkeklerin kadınlara daha çok geliştirici amaçlı sanal kaytarma yaptıkları görülmüştür. Aynı şekilde Çavuşoğlu vd., (2014) erkeklerin kadınlara göre daha fazla bankacılık/finans/alışveriş gibi önemsiz sayılabilecek davranışlarda bulunduğu görülmüştür. Ancak Çavuşoğlu vd., (2014) diğer tüm sanal kaytarma davranışlarında kadınların erkeklere göre daha fazla bulundukları görülmüştür. Özkalp vd., (2012) yaptıkları çalışmada kadınların erkeklere göre daha fazla sanal kaytarma davranışlarında (özellikle yazılı mesajlaşma) bulundukları görülmüştür. Akça (2013), Kaplan ve Çetinkaya (2014), Ünal vd.,(2015), Ulusoy ve Benli (2017) ve Kırtay (2019) çalışmalarında sanal kaytarma davranışlarının cinsiyet açısından anlamlı bir farklılık göstermediği sonucuna varmıştır.

\section{SONUC VE ÖNERILER}

Tüm ülkelerde hem bireysel hem de örgütsel açıdan önemli bir yere sahip olan sanal kaytarma, gelecek dönemlerde de teknolojiye bağımlılık artıkça önem kazanacağı ve önemli bir sorun olacağı düşünülmektedir. Hem kamu hem özel sektörde önemli bir sorun olarak görülen sanal kaytarma boyutunun, ortalama süresinin ve nedenlerinin belirlenmesi büyük önem arz etmekte olup sanal kaytarma davranışlarının azaltılması için izlenecek politikaların hazırlanmasında esas teşkil etmektedir.

Son dönemlerde sanal kaytarma davranışlarını belirlemeye yönelik çalışmasında önemli artış görülmüştür. Bu çalışmada da sağlık çalışanlarının sanal kaytarma faaliyetlerine göre haftalık mesai süresi içerisinde ne kadar sanal kaytarma yaptıklarını tespit etmeye yönelik bir çalışma olmuştur.

Çalışma sonuçları şöyle sıralanabilir;

- Sağlık çalışanlarının tamamına yakının evinde, cep telefonunda ve işyerinde internet bulunmaktadır.

- Örneklemdeki sağlık çalışanları kişi başı günlük ortalama 203 dakikasını, haftalık (7 gün) 1427 dakikasını sanal âlemde geçirmektedir. Bu süre yaklaşık haftada bir gün (23,6 saat) etmektedir.

- Sağlık çalışanları haftalık mesai süresi içerisinde (2400 dk) yaklaşık bir günlük mesaisini (452 dk: 7,5 saat), mesai süresinin \%20'sini sanal kaytarma yaparak geçirmektedir.

- Bir saate yaklaşan süreleriyle en fazla zaman alan sanal kaytarma faaliyetleri; kişisel sosyal medya araçlarını kullanma (54 dk) ve dizi, film, maç vb. programları izleme (52 dk) etkinliğidir.

- Sosyal medya araçlarını kullanmada; İdari personel ve lise mezunları daha fazla "yazılım programı indirmede", 50 yaş ve üzeri olanlar ile 21 yıldan fazla çalışanlar daha az "Kişisel sosyal medya araçlarını kullanmada", 21 yıl ve üzeri çalışanlar daha az "E-kitap okumada" ve geliri altı bin liranın üzerinde olanlar daha fazla "haber sitelerinde dolanmada" diğer gruplardan farklılaşmaktadır. 
Süleyman Demirel Üniversitesi Vizyoner Dergisi, Yıl: 2020, Cilt: 11, Sayı: Ek, 29-41.

Süleyman Demirel University Visionary Journal, Year: 2020, Volume: 11, No: Supplement, 29-41.

- Genel olarak erkekler kadınlardan daha uzun süre sanal kaytarma yapmaktadır.

- Fakat "telefonla görüşme”, "alış veriş sitelerini dolanma", "kişisel hobiler hakkında bilgi edinme”, "müzik dinleme" ve "kişisel sosyal medya araçlarını kullanma" faaliyetlerinde süre açısından kadın- erkek ayrımı bulunmamaktadır.

İşletmelerde sanal kaytarmayı faaliyetlerini ortadan kaldırma ve sanal kaytarma sürelerini sıfırlama imkânı olmadığı düşünülmektedir. Yine sağlık çalışanlarının sanal kaytarma davranışlarını makul bir süre içerisinde tutmak, işleri aksamasını önlemek ve personelin kendini geliştireceği şekilde yönlendirmek gereklidir. Araştırmacıların gözlemleri, diyalogları ve çalışma veriler doğrultusunda aşağıdaki öneriler geliştirilmiştir.

- Sağlık çalışanlarında sanal kaytarma faaliyetlerinin neler olduğu, sanal kaytarmayla israf edilen süreler, sağlık kurumu ve hastalar açısından ortaya çıkarabilecek sorunlar hakkında farkındalık oluşturulmalı,

- Sanal kaytarma ve dijital teknolojileri doğru kullanma konularında eğitimler, çalışma ofisleri ve sanal ortamlarda uyarı ve duyurular yapılmalı,

- Mesai süresi içerisinde bir saatten daha fazla sanal kaytarma yapan \%8,9'luk bir çalışan kitlesi bulunmaktadır. Bu kitleyi oluşturan sağlık çalışanları özel olarak tespit edilmeli ve hizmet içi eğitime alınmalı,

- Sağlık çalışanları mesai süresi içerisindeki işleri olmadığı zamanları, kendi mesleki ve kişiliklerini geliştirebilecekleri sanal faaliyetlerle değerlendirmeye özendirilmeli,

- İletişim teknoloji kullanımı ile ilgili denetimlerin artırılıp ve gündemde tutulmalı,

- Sanal kaytarma davranışlarını engellemek için kısıtlayıcı programlarının kurulması ve güncellenmelerin sağlanması gereklidir.

\section{KAYNAKÇA}

Akca, A. (2013). Okul yöneticilerinin iş dışı internet kullanım (siber aylaklık) davranışlarının incelenmesi. Yüksek Lisans Tezi, Yıldız Teknik Üniversitesi Sosyal Bilimler Enstitüsü, İstanbul.

Bacaksız, F.E., Tuna, R. ve Harmancı, S. A. (2018). Sanal kaytarmaya karşı evde çalışma:Hemşire akademisyenler üzerinde bir araştırma. Dokuz Eylül Üniversitesi Hemşirelik Fakültesi Elektronik Dergisi, 11(3), 241-249.

Blanchard, A. L. ve Henle, A. C. (2008). Correlates of different forms of cyberloafing: The role of norms and external locus of control. Computers in Human Behaviour, 24, 1067-1084.

Candan, H. ve İnce, M. (2016). Siber kaytarma ve örgütsel bağlılık arasındaki ilişkinin incelenmesine yönelik emniyet çalışanları üzerine bir araştırma. Niğde Üniversitesi İktisadi ve İdari Bilimler Fakültesi Dergisi, 9(1), 229-235.

Carlson, J. R., Zivnuska, S., Harris, R. B., Harris, K. J., ve Carlson, D. S. (2016). Social media use in the workplace: A study of dual effects. Journal of Organizational and End User Computing, 28(1), 15-31.

Coşkun, R., Altunışık, R. ve Yıldırım, E. (2017). Sosyal bilimlerde araştırma yöntemleri (SPSS Uygulamalı). Adapazarı: Sakarya Kitabevi.

Çavuşoğlu, S., Palamutçuoğlu, B. ve Palamutçuoğlu, B. T. (2014). Çalışanların demografik özelliklerinin sanal kaytarma üzerindeki etkisi: üniversite çalışanları üzerinde ampirik bir araştırma. Research Journal of Busines Management, 1(3), 2148-6689.

Demir, M. ve Tan, M. (2018). İşgörenlerin demografik özellikleri ve sanal kaytarma davranışı arasındaki ilişki. Journal of Tourism Theory and Research, 4(1), 40-56. doi:10.24288/jttr.37579.

Doorn, O.V. (2011). Cyberloafing: A multi-dimensional construct placed in a theoretical framework. Masters Thesis, Eindhoven University of Technology, Department Industrial Engineering and Innovation Sciences.

Filiz, F. (2017). Kamu hastane birliklerinin ülke sağlık politikalarına katkısını belirlemede sağlık personelinin algısı: Sivas ili örneği. Yüksek Lisans Tezi, Cumhuriyet Üniversitesi Sosyal Bilimler Enstitüsü, Sivas. 
Süleyman Demirel Üniversitesi Vizyoner Dergisi, Yıl: 2020, Cilt: 11, Sayı: Ek, 29-41.

Süleyman Demirel University Visionary Journal, Year: 2020, Volume: 11, No: Supplement, 29-41.

Filiz, M. ve Bardakçı, S. (2020). Sağlık çalışanlarının örgütsel iklim algıları ve örgütsel güven düzeyleri arasındaki ilişkinin incelenmesi: Artvin ili örneği. Elektronik Sosyal Bilimler Dergisi, 19(73), 436-449.

Garrett, R. K. ve Danziger, J. N. (2008). On cyberslacking: Workplace status and personal Internet use at work. Cyber Psychology \& Behavior, 11(3), 287-292.

George, D. ve Poul M. (2016). IBM SPSS statistics 23 step by step. A simple guide and reference. New York: Routledge, Fourteenth.

Gürbüz, S. ve Şahin, F. (2014). Sosyal bilimlerde araştırma yöntemleri. 2. Baskı, Ankara: Seçkin Yayıncılık.

Hair, J. F., Sarstedt, M., Ringle, C. M. ve Mena, J. A. (2012). An assessment of the use of partial least squares structural equation modeling in marketing research. J. Of the Acad. Mark. Sci, 40, 414-433.

Hassan, H. M., Reza, D. M. ve Farkhad, M. A. (2015). An experimental study of influential elements on cyberloafing from general deterrence theory perspective case study: Tehran subway organization. International Business Research, 8(3), 91-98.

Kalaycı, E. (2010). Üniversite Öğrencilerinin Siber Aylaklık Davranışları ile Öz Düzenleme Stratejileri Arasındaki İlişkinin Incelenmesi. Yüksek Lisans Tezi, Hacettepe üniversitesi Fen Bilimleri Enstitüsü, Ankara.

Kaplan, M. ve Çetinkaya, A. Ş. (2014). Sanal kaytarma ve demografik özellikler açısından farklılıklar: Otel işletmelerinde bir araştırma. Turizm Araştırmaları Dergisi, 25(1), 26-34.

Karagöz, Y. (2017). SPSS ve AMOS uygulamalı bilimsel araştırma yöntemleri ve yayın etiği. Ankara: Nobel Yayın Dağıtım.

Keklik, B., Kılıç, R., Yıldız, H. ve Yıldız, B. (2015). Sanal kaytarma davranışlarının örgütsel öğrenme kapasitesi üzerindeki etkisinin incelenmesi, Business and Economics Research Journal, 6(3), 129.

Kırtay, Ç. (2019). Kamu çalışanlarının sanal kaytarma davranışları: Yalova üniversitesi örneği. Yüksek Lisans Tezi, Yalova Üniversitesi Sosyal Bilimler Enstitüsü, Yalova.

Köse, S., Oral, L. ve Türesin, H. (2012). İş yaşamında sosyal kolaylaştırma kavramı ve sanal kaytarma ile ilişkisi: Araştırma görevlileri üzerinde bir araştırma. Sosyal ve Beşeri Bilimler Dergisi, 4(1), 287-295.

Liberman, B .S., McKenna, G. K. ve Buffardi, L. E. (2011). Employee job attitudes and organizational characteristics as predictors of cyberloafing. Computers in Human Behavior, 27, 2192-2199.

Lim, V. K. (2002). The it way of loafing on the job: Cyberloafing, neutralizing and organizational justice. Journal of Organizational Behavior, 23,675-694.

Lim, V. K. ve Teo, T. S. (2005). Prevalence, perceived seriosness justification and regulation of cyberloafing in singapore-an explatory study. Information\&Management, 42, 1081-1093.

Lim, V. K., Teo, T. S. ve Loo, G. L. (2002). How do I loaf here? Let me count the ways. Communications of the ACM, 45(1), 66-70.

Morahan-Martin, J. (2001). Caught in the web: Research and criticism of internet abuse with application to college students. C. R. Wolfe (Ed.), Learning and teaching on the world wide web içinde (191-219). San Diego, CA: Academic Press.

Önsal, N. (2012). Endüstri ilişkileri sözlüğü. Türkiye işçi sendikaları konfederasyonu. Ankara: Aydoğdu Ofset.

Örücü, E. ve Yıldız, H. (2014). İşyerinde kişisel internet ve teknoloji kullanımı: Sanal kaytarma. Ege Akademik Bakış, 14(1), 99-114.

Özdamar, K. (1999). Paket programlar ile istatistiksel veri analizi 1, 2. Baskı. Eskişehir: Kaan Kitabevi.

Özdem, G. ve Demir, A. (2015). Okul yöneticilerinde sanal kaytarma davranışları. Mersin Üniversitesi Ĕgitim Fakültesi Dergisi, 11(3), 1029-1042.

Özkalp, E., Aydın, U. ve Tekeli, S. (2012). Sapkın örgütsel davranışlar ve çalışma yaşamında yeni bir olgu: Sanal kaytarma (cyberloafing) ve iş ilişkilerine etkileri. Çimento Iş̧veren Dergisi, 26(2), 18-33. 
Süleyman Demirel Üniversitesi Vizyoner Dergisi, Yıl: 2020, Cilt: 11, Sayı: Ek, 29-41.

Süleyman Demirel University Visionary Journal, Year: 2020, Volume: 11, No: Supplement, 29-41.

Restubog, S. L., Garcia, P. M., Toledano, L. S., Amarnani, R. K., Tolentino, L. R. ve Tang, R. L. (2011). Yielding to (cyber)-temptation: Exploring the buffering role of self-control in the relationship between organizational justice and cyberloafing behavior in the workplace. Journal of Research in Personality, 45(2), 247-251.

Seymour, L. ve Nadasen , K. (2007). Web access for it staff: A developing world perspective on web abuse. The Electronic Library, 25(5), 543-557.

Tabachnick, B. G. ve Fidell, L.S. (2013). Using multivariate statistics (5th ed.). New York: Allyn and Bacon.

Uçar, N. (2006). Parametrik olmayan hipotez testleri. Ş. Kalaycı (Ed.), SPSS uygulamalı çok değişkenli istatistik teknikleri içinde (85-112), Ankara: Asil Yayın Dağıtım.

Ulusoy, H. ve Benli, D. G. (2017). Akademisyenlerin sanal kaytarma davranışları: Bir kamu üniversitesi örneği. Uluslararası Sosyal Araştırmalar Dergisi, 10(54), 924-934.

Ünal, Ö. F. ve Tekdemir, S. (2015). Sanal kaytarma: Bir kamu kurumunda ampirik bir araştırma. Süleyman Demirel Üniversitesi İktisadi ve İdari Bilimler Fakültesi Dergisi, 20(2), 95-118.

Ünal, Ö. F., Tekdemir, S. ve Yaldızbaş, S. (2015). Kamu çalışanlarının sanal kaytarma amaçları üzerine ampirik bir araştırma. Çankırı Karatekin Üniversitesi Sosyal Bilimler Enstitüsü Dergisi, 6(2), 515-534.

Vitak, J., Crouse, J. ve LaRose, R. (2011). Personal internet use at work: Understanding cyberslacking. Computers in Human Behavior, 27(5), 1751-1759.

Weatherbee, T. G. (2010). Counterproductive use of technology at work: Information and communications technologies and cyberdeviancy. Human Resource Management Review, 20, 35-44. 